\title{
Monitoring patients with juvenile idiopathic arthritis using health-related quality of life
}

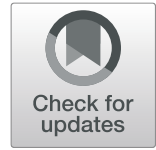

Martijn J. H. Doeleman ${ }^{1,2^{*+}}$ (D), Sytze de Roock ${ }^{1,2+}$, Nathan Buijsse ${ }^{1,2}$, Mark Klein ${ }^{1}$, Gouke J. Bonsel ${ }^{3,4}$, Vicki Seyfert-Margolis ${ }^{5}$, Joost F. Swart ${ }^{1,2}$ and Nico M. Wulffraat ${ }^{1,2}$

\begin{abstract}
Background: Pediatric patients with juvenile idiopathic arthritis (JIA) are at risk for a lower health-related quality of life compared to their healthy peers. Remote monitoring of health-related quality of life using electronic patientreported outcomes could provide important information to treating physicians. The aim of this study was to investigate if self-assessment with the EuroQol five-dimensional 'youth' questionnaire with five levels (EQ-5D-Y-5 L) inside a mobile E-health application could identify JIA patients in need of possible treatment adjustments.

Methods: The EQ-5D-Y-5 L was completed via a mobile application (Reuma2Go) between October 2017 and January 2019. The clinical juvenile arthritis disease activity score with 71 joint count (cJADAS-71) was reported at every corresponding visit as reference for disease activity. Previously described cJADAS-71 thresholds were used to identify patients in possible need of treatment adjustments. Discriminatory power of the EQ-5D-Y-5 $L$ was assessed by ROC-curves and diagnostic characteristics.
\end{abstract}

Results: Sixty-eight JIA patients completed the EQ-5D-Y-5 L questionnaire. Median cJADAS-71 indicated low disease activity overall in the studied population. ROC curves and diagnostic characteristics demonstrated that selfassessment with the EQ-5D-Y-5 L could distinguish between patients with inactive disease (or minimal disease activity) and moderate to high disease activity with good accuracy (87\%), sensitivity (85\%), specificity (89\%) and negative predictive value (86\%).

Conclusions: Results demonstrate that the EQ-5D-Y-5 L was able to identify JIA patients in need of possible treatment adjustments in our studied population. Remote monitoring of health-related quality of life and patientreported outcomes via E-health applications could provide important additional information to determine the frequency of clinical visits, assess therapeutic efficacy and guide treat-to-target strategies in pediatric patients with JIA.

Keywords: Juvenile idiopathic arthritis, Health-related quality of life, EQ-5D-Y-5 L, Disease activity, Remote monitoring, Mobile applications, E-health

\footnotetext{
* Correspondence: m.j.h.doeleman@umcutrecht.nl

${ }^{\dagger}$ Martijn J.H. Doeleman and Sytze de Roock contributed equally as co-first authors

${ }^{1}$ Department of Pediatric Immunology and Rheumatology, Wilhelmina

Children's Hospital, University Medical Center Utrecht, P.O. Box 85090, 3508,

$A B$, Utrecht, The Netherlands

${ }^{2}$ Faculty of Medicine, Utrecht University, Utrecht, The Netherlands

Full list of author information is available at the end of the article
}

(c) The Author(s). 2021 Open Access This article is licensed under a Creative Commons Attribution 4.0 International License, which permits use, sharing, adaptation, distribution and reproduction in any medium or format, as long as you give appropriate credit to the original author(s) and the source, provide a link to the Creative Commons licence, and indicate if changes were made. The images or other third party material in this article are included in the article's Creative Commons licence, unless indicated otherwise in a credit line to the material. If material is not included in the article's Creative Commons licence and your intended use is not permitted by statutory regulation or exceeds the permitted use, you will need to obtain permission directly from the copyright holder. To view a copy of this licence, visit http://creativecommons.org/licenses/by/4.0/ The Creative Commons Public Domain Dedication waiver (http://creativecommons.org/publicdomain/zero/1.0/) applies to the data made available in this article, unless otherwise stated in a credit line to the data. 


\section{Background}

Over the past two decades, the use of biologic therapies has substantially improved disease control and outcome for patients with juvenile idiopathic arthritis (JIA). Nevertheless, patients with JIA are still at risk for a significantly worse health-related quality of life (HRQoL) when compared to their healthy peers [1-4]. Persisting pain and fatigue, recurrent disease activity, and impaired societal participation remain issues for many patients with JIA [5-7]. This emphasizes the importance of adequately monitoring HRQoL.

Although several patient-reported outcomes (PROs) include measures for HRQoL, such as the Pediatric Quality of Life Inventory Rheumatology Module version 3.0 [8] and the Juvenile Arthritis Multidimensional Assessment Report (JAMAR) [9], most of these measures are extensive and require clinical visits. Therefore, frequent application required for detailed monitoring can be difficult, especially with pediatric patients.

In contrast to these disease-specific measures, the EuroQol five-dimensional 'youth' questionnaire (EQ-5D$\mathrm{Y}$ ) is a generic measure of HRQoL that takes approximately 1-2 min to complete and has demonstrated to be a valid and feasible instrument to monitor HRQoL in children and adolescents with JIA and other chronic conditions [10-12]. Recently, the EQ-5D-Y has been extended by the EuroQol Group to a five-level classification system (EQ-5D-Y-5L), hereby reducing ceiling effects and improving discriminatory power [13-16].

In order to facilitate remote monitoring and frequent self-assessment of PROs, we have recently developed a mobile E-health application, called "Reuma2Go". The mobile application includes the EQ-5D-Y-5L as measurement of HRQoL. Since current treat-to-target guidelines recommend incorporation of PROs and HRQoL in patient assessment and therapeutic decisions [17], the present study aimed to investigate if remote selfassessment with the EQ-5D-Y-5L could identify JIA patients in need of possible treatment adjustments.

\section{Methods}

\section{Study design and participants}

The study was designed as a retrospective monocentric study using pseudonymized data from the Reuma2Go application and electronic health records, and was performed in accordance with the Declaration of Helsinki. This study did not fall under the scope of the Medical Research Involving Human Subjects Act, as declared by the locally appointed ethics committee at our hospital (no. 16-361C).

Patients with a diagnosis of JIA according to the International League of Associations for Rheumatology classification criteria [18] visiting our hospital between October 2017 and January 2019 were included in the study. Patients were included regardless of age, JIA subcategory, disease duration, disease activity or therapy. Informed consent for the Reuma2Go application was obtained from all parents and children of 12 years and older. Standard practice was not influenced by data from the Reuma2Go during the study period.

\section{Study instruments}

A mobile version of the EQ-5D-Y-5L was completed in the Dutch language on the Reuma2Go application (See Supplementary Figures S1-S7, Additional File 1). The EQ-5D-Y-5 L is a five-level classification system to measure HRQoL consisting of five domains on mobility, selfcare, daily activities, pain/discomfort, and anxiety/depression [13]. Each domain can be scored on a five-level ordinal scale: 1 = 'no problems', 2 = 'slight problems', 3 = 'moderate problems', 4 = 'severe problems', 5 = 'extreme problems / inability to perform function'. Finally, the respondent is asked to rate his/her current health on a visual analogue scale (VAS) ranging from $0=$ 'the worst health you can imagine' to 100 = 'the best health you can imagine' (EQ-VAS) [19]. Patients with inactive disease (cJADAS range 0-0.1) scoring level $1=$ 'no problems' on every domain of the EQ-5D-Y-5 L accompanied by the lowest possible EQ-VAS, indicating 'the worst health you can imagine', were excluded from analysis because we could not be certain if they misinterpreted the EQ-VAS. The participant's response can be conveniently summarised by an unweighted sum of the individual level scores (EQ-5D sum score) ranging from 5 to 25; or an overall EQ5D-utility score (further discussed elsewhere [15]). Responses were analysed when completed within two weeks prior to a clinical visit without any event in between. The first eligible EQ-5D-Y-5L response and its respective visit was included for patients who completed multiple questionnaires at multiple visits. In the current version of the Reuma2Go application it is not registered who completes the questionnaires (parent or patient).

As part of standard clinical care, the clinical juvenile arthritis disease activity score with 71 joint-count (cJADAS-71) is reported by the treating pediatric rheumatologist at each clinical visit [20]. The cJADAS-71 is a composite measure of disease activity and consists of the sum of its three components: an active joint count (AJC); a physician's global assessment of disease activity (PGA), measured on a $0-10$ VAS where $0=$ 'no activity' and 10 = 'maximum activity'; and a patient/parent assessment of overall well-being, measured on a 0-10 VAS where $0=$ 'best' and $10=$ 'worst'.

In line with current treat-to-target guidelines and previously proposed cJADAS-71 cut-off values corresponding to a disease activity state of moderate to high disease activity, patients in need of possible treatment 
adjustments were defined as cJADAS-71 $>1.5$ and $>2.5$ for oligoarthritis and polyarthritis, respectively $[17,21]$.

\section{Statistical analysis}

Baseline characteristics were analysed using descriptive statistics. Included patients were divided into two groups according to cJADAS-71 cut-off values as described above. Differences in proportions between groups were examined by Fisher's exact test. Mann-Whitney U was used to test differences for continuous variables, as appropriate. To test for statistically significant differences between proportion of reported problems, EQ-5D-Y-5L responses were dichotomized into 'no problems' or 'any problems'. For the primary objective, discriminatory power of the EQ-5D-Y-5L was examined by computing Receiver Operating Characteristic (ROC) curves and area under the curve (AUC) for each individual EQ-5D-Y-5L domain, the EQ-VAS and the unweighted EQ-5D sum score. Optimal threshold were selected using Youden's Index [22] and further analysed by calculating accuracy, sensitivity, specificity, positive predictive value, and negative predictive value. All statistical analyses were two-sided with $p$-values $<0.05$ considered as statistically significant. Analyses were performed using $\mathrm{R}$ version 3.5.1 with packages 'pROC' version 1.16.1 and 'caret' version $6.0-85$ [23].

\section{Results}

During the study period, 72 patients completed the EQ5D-Y-5L questionnaire via the Reuma2Go application within a median of 0 days (IQR $0-4$ ) prior to their clinical visit. Four patients with inactive disease scoring 'no problems' on every level of the EQ5D, while also scoring the highest EQ-VAS being "the worst health you can imagine" were excluded from the analysis because we could not be certain if they misinterpreted the EQ-VAS. Most of the remaining 68 patients were female $(69 \%)$ and were diagnosed with persistent oligoarticular JIA (40\%). Disease duration was significantly shorter in JIA patients with moderate to high disease activity according to the specific cut-off values for oligo and polyarticular JIA ( $p$ -

Table 1 Characteristics of included patients

\begin{tabular}{|c|c|c|c|}
\hline & Total & CJADAS-71 $<=1.5$ or $<=2.5^{a}$ & CJADAS-71 $>1.5$ or $>2.5^{b}$ \\
\hline Patients, n (\%) & 68 & 35 & 33 \\
\hline Female, n (\%) & $47(69)$ & $24(69)$ & $23(70)$ \\
\hline \multicolumn{4}{|l|}{ JIA Subcategory, n (\%) } \\
\hline Oligoarticular JIA persistent & $27(40)$ & $12(34)$ & $15(45)$ \\
\hline Oligoarticular JIA extended & $6(9)$ & $3(9)$ & $3(9)$ \\
\hline Polyarticular JIA RF- & $15(22)$ & $9(26)$ & $6(18)$ \\
\hline Polyarticular JIA RF+ & $5(7)$ & $1(3)$ & $4(12)$ \\
\hline Psoriatic Arthritis & $7(10)$ & $6(17)$ & $1(3)$ \\
\hline Enthesitis Related Arthritis & $5(7)$ & $2(6)$ & $3(9)$ \\
\hline Systemic JIA & $1(2)$ & $1(3)$ & $0(-)$ \\
\hline Undifferentiated JIA & $2(3)$ & $1(3)$ & $1(3)$ \\
\hline Age at visit, median (IQR), y & $13.6(10.5-16.4)$ & $13.3(11.0-15.6)$ & $14.1(9.0-16.9)$ \\
\hline Age at disease onset, median (IQR), y & $7.6(3.1-12.1)$ & $6.7(3.0-11.2)$ & $9.4(3.4-13.6)$ \\
\hline Disease duration, median (IQR), y & $4.6(1.5-7.7)$ & $6.4(2.7-8.4)$ & $2.4(1.2-6.3)$ \\
\hline cJADAS-71, median (IQR) & $1.8(0.1-6.1)$ & $0.1(0.0-0.7)$ & $6.5(4.0-9.5)$ \\
\hline \multicolumn{4}{|l|}{ Treatment at Visit } \\
\hline \multicolumn{4}{|l|}{ Biologic DMARD, n (\%) } \\
\hline Adalimumab & $17(25)$ & $10(29)$ & $7(21)$ \\
\hline Etanercept & $8(12)$ & $4(11)$ & $4(12)$ \\
\hline Golimumab & $4(6)$ & $0(-)$ & $4(12)$ \\
\hline \multicolumn{4}{|l|}{ Synthetic DMARD, n (\%) } \\
\hline Methotrexate & $30(44)$ & $17(49)$ & $13(39)$ \\
\hline Other DMARD & $5(7)$ & $3(9)$ & $2(6)$ \\
\hline No Biologic or Synthetic DMARD n (\%) & $24(35)$ & $12(34)$ & $12(36)$ \\
\hline
\end{tabular}

CJADAS-71: clinical juvenile arthritis disease activity score with 71 joint count; DMARD: disease modifying anti-rheumatic drug; IQR: interquartile range. ${ }^{\text {LLow }}$ disease activity for oligoarticular or polyarticular JIA, respectively. ${ }^{\text {b }}$ Moderate or high disease activity for oligoarticular or polyarticular JIA, respectively 
value $=0.01$ ). Characteristics of all included patients are presented in Table 1.

EQ-5D-Y-5L responses were without missing values. The proportion of patients reporting 'no problems' vs. 'any problems' was significantly different for all five EQ$5 \mathrm{D}-\mathrm{Y}-5 \mathrm{~L}$ domains between the two patient groups $(p-$ values $<0.001$ ), as was the difference in EQ-VAS responses and total EQ-5D sum score (Table 2).

ROC curves demonstrated the discriminatory power of the EQ-5D sum score (AUC 0.91, 95\% CI 0.84-0.99) regarding identification of JIA patients with moderate to high disease activity (Fig. 1). ROC curves of individual

Table 2 EQ-5D-Y-5L responses of included patients

\begin{tabular}{|c|c|c|c|}
\hline & Total & CJADAS-71 $<=1.5$ or $<=2.5$ & CJADAS-71 $>1.5$ or $>2.5$ \\
\hline EQ-5D-Y-5L Domains & $n=68$ & $n=35$ & $n=33$ \\
\hline \multicolumn{4}{|l|}{ Q01 Mobility (Walking)* } \\
\hline No problems & 44 & 34 & 10 \\
\hline Slight problems & 13 & 1 & 12 \\
\hline Moderate problems & 5 & 0 & 5 \\
\hline Severe problems & 6 & 0 & 6 \\
\hline Unable & 0 & 0 & 0 \\
\hline \multicolumn{4}{|l|}{ Q02 Self-Care (Washing or Dressing)* } \\
\hline No problems & 54 & 35 & 19 \\
\hline Slight problems & 10 & 0 & 10 \\
\hline Moderate problems & 4 & 0 & 4 \\
\hline Severe problems & 0 & 0 & 0 \\
\hline Unable & 0 & 0 & 0 \\
\hline \multicolumn{4}{|l|}{ Q03 Daily Activities* } \\
\hline No problems & 33 & 27 & 6 \\
\hline Slight problems & 22 & 8 & 14 \\
\hline Moderate problems & 7 & 0 & 7 \\
\hline Severe problems & 5 & 0 & 5 \\
\hline Unable & 1 & 0 & 1 \\
\hline \multicolumn{4}{|l|}{ Q04 Pain* } \\
\hline No pain or discomfort & 33 & 28 & 5 \\
\hline Slight pain or discomfort & 17 & 7 & 10 \\
\hline Moderate pain or discomfort & 11 & 0 & 11 \\
\hline Severe pain or discomfort & 7 & 0 & 7 \\
\hline Extreme pain or discomfort & 0 & 0 & 0 \\
\hline \multicolumn{4}{|l|}{ Q05 Anxiety / Depression* } \\
\hline Not worried, sad, or unhappy & 46 & 33 & 13 \\
\hline Slightly worried, sad, or unhappy & 16 & 2 & 14 \\
\hline Moderately worried, sad, or unhappy & 5 & 0 & 5 \\
\hline Severely worried, sad, or unhappy & 1 & 0 & 1 \\
\hline Extremely worried, sad, or unhappy & 0 & 0 & 0 \\
\hline \multicolumn{4}{|l|}{ EQ-VAS $(0-100)^{* *}$} \\
\hline median (IQR) & $81.5(69.3-96.5)$ & $96(89-100)$ & $70(40-76)$ \\
\hline \multicolumn{4}{|l|}{ EQ-5D Sum Score $(5-25)^{* *}$} \\
\hline median (IQR) & $6(5-10)$ & $5(5-6)$ & $10(7-14)$ \\
\hline
\end{tabular}

* $p$-value $<0.001$ by Fisher's exact when responses were dichotomized into 'no problems' vs. 'any problems'

${ }^{* *} p$-value $<0.001$ by Mann-Whitney $U$ test

CJADAS-71: clinical juvenile arthritis disease activity score with 71 joint count; EQ-5D-Y-5L: EuroQol five-dimensional 'youth' questionnaire with five levels; IQR:

interquartile range 


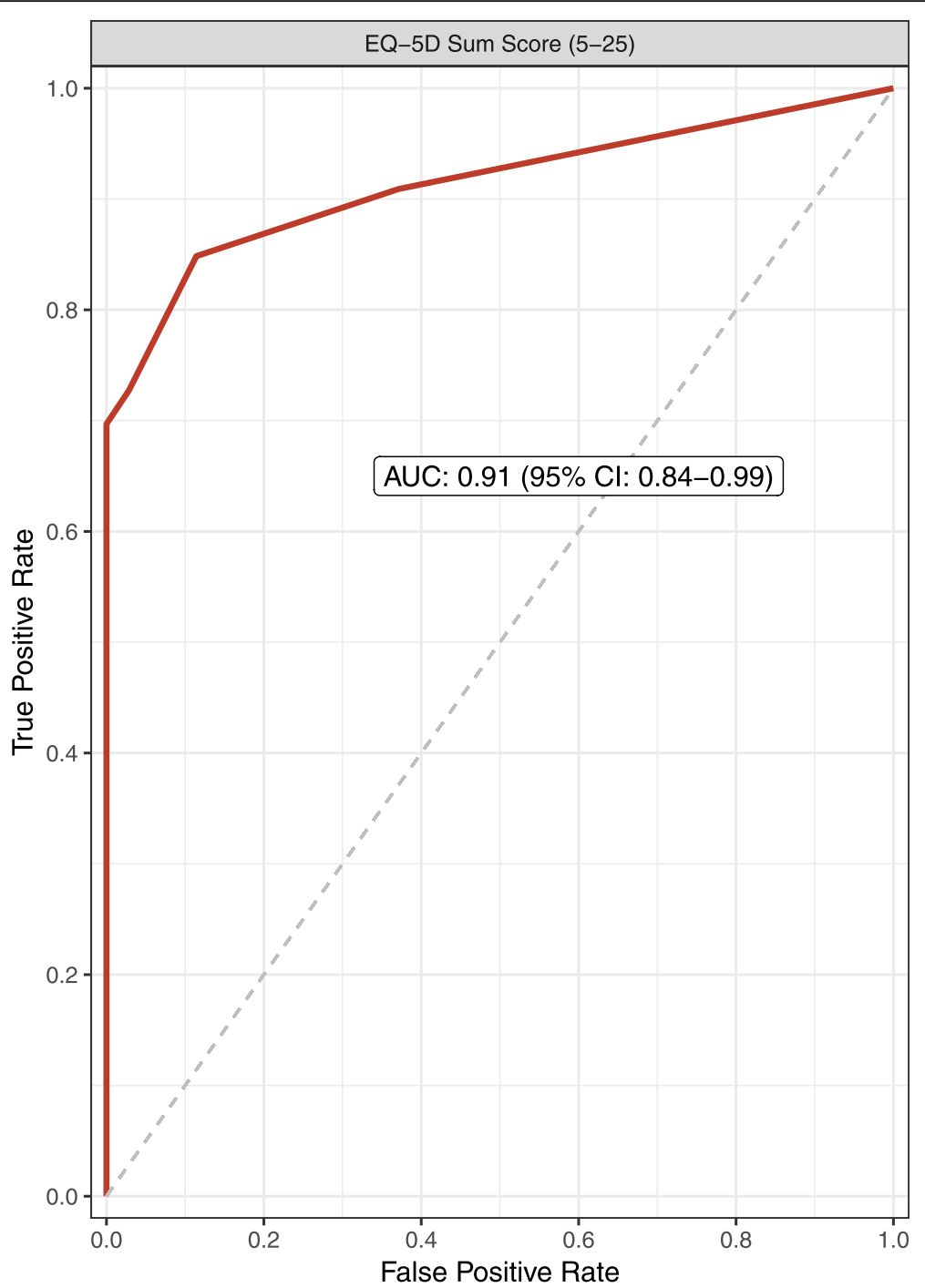

Fig. 1 Discriminatory power of the EQ-5D-Y-5L sum score to identify moderate to high disease activity. AUC: area under the curve

Table 3 Discriminatory power of EQ-5D-Y-5L thresholds to identify JIA patients with moderate to high disease activity

\begin{tabular}{|c|c|c|c|c|c|c|}
\hline EQ-5D-Y-5L Thresholds & Accuracy (\%) & $95 \% \mathrm{Cl}$ & Sensitivity (\%) & Specificity (\%) & PPV (\%) & NPV (\%) \\
\hline EQ-5D Sum Score $>6$ & $87^{*}$ & $76-94$ & 85 & 89 & 88 & 86 \\
\hline EQ-VAS $<82$ & $87^{*}$ & $76-94$ & 88 & 86 & 85 & 88 \\
\hline Mobility > 1 & $84^{*}$ & 75-93 & 70 & 97 & 96 & 77 \\
\hline Self-Care > 1 & $72^{*}$ & $60-88$ & 42 & 100 & 100 & 65 \\
\hline Daily Activities > 1 & $79^{*}$ & $68-88$ & 82 & 77 & 77 & 82 \\
\hline Pain/Discomfort > 1 & $82^{*}$ & $71-91$ & 85 & 80 & 80 & 85 \\
\hline Anxiety/Depression > 1 & $78^{*}$ & $66-87$ & 61 & 94 & 91 & 72 \\
\hline
\end{tabular}

${ }^{*} P$-value < 0.001; EQ-5D-Y-5L: EuroQol five-dimensional 'youth' questionnaire with five levels; EQ-5D sum score: unweighted sum of EQ-5D-Y-5L individual level scores (range 5-25); EQ-VAS: EuroQol visual analogue scale (range 0-100); NPV: negative predictive value; PPV: positive predictive value 
EQ-5D-Y-5L domains and EQ-VAS are presented in the Supplementary Info (See Supplementary Figures S8A-F, Additional File 1).

Optimal thresholds were identified using Youden's Index. The EQ-5D sum score and EQ-VAS displayed comparable diagnostic accuracy (87\%). Full diagnostic characteristics are presented in Table 3.

\section{Discussion}

The EQ-5D-Y-5L completed via the Reuma2Go application was able to identify JIA patients with moderate to high disease activity in need of possible treatment adjustments. The EQ-5D sum score could identify these patients with satisfactory accuracy, sensitivity and negative predictive value. Thus far, our data indicate that disease activity requiring treatment changes would not have been missed using the identified thresholds. Therefore, the Reuma2Go application could provide physicians with important information without the requirement of a clinical visit. This could be especially useful in regions or situations where regular out-patient clinic visits are not feasible.

Future research should elaborate on the safety of remote monitoring and optimizing visit frequency of JIA patients in remission on medication, as well as the costeffectiveness of such interventions. Long-term usage of Ehealth applications and their effect on self-management, disease assessment and physician-patient interaction will be investigated. Also, addition of the identity of the respondent (parent or patient) may further improve the results. Recent studies on interactive technologies to promote disease self-management have demonstrated feasibility and initial results warrant future research of such interventions $[24,25]$.

Our results are subject to limitations connected to a population with overall low disease activity and a relatively small sample size. This forced us to dichotomize the answers into "no problems" and "any problems", and prevented further sub-group analyses of patients that indicated any problems. Prolonged data collection is necessary to investigate the responsiveness and reliability of the EQ-5D-Y-5L. These results confirm the relationship of HRQoL with disease severity found in previous studies [11, 26, 27].

\section{Conclusions}

In summary, initial results illustrate the value of selfassessment and E-health applications for remote monitoring of patients with JIA. Monitoring of PROs and HRQoL through smart devices could revolutionize information collection and contribute to a continuum of care for patients with JIA. Simultaneously, this provides physicians with important information to determine the frequency of clinical visits, assess therapeutic efficacy and guide treat-to-target strategies.

\section{Abbreviations}

AJC: Active Joint Count; AUC: Area Under the Curve; CJADAS-71: clinical Juvenile Arthritis Disease Activity Score with 71 joint count; EQ-5D-Y-5 $\mathrm{L}$ : EuroQol five-dimensional 'Youth' questionnaire with five levels; HRQoL: Health-related Quality of Life; JAMAR: Juvenile Arthritis Multidimensional Assessment Report; JIA: Juvenile Idiopathic Arthritis; NPV: Negative Predictive Value; PGA: Physician Global Assessment; PPV: Positive Predictive Value; PRO: Patient-reported Outcome; ROC curve: Receiver Operating Characteristic curve; VAS: Visual Analogue Scale

\section{Supplementary Information}

The online version contains supplementary material available at https://doi. org/10.1186/s12969-021-00527-z.

Additional file 1. Information and screenshots on the EQ-5D-Y-5 L questionnaire as presented in the Reuma2go mobile application. ROC curves of individual EQ-5D-Y-5 L domains and EQ-VAS to identify JIA patients with moderate to high disease activity.

\section{Acknowledgements}

The EQ-5D-Y-5 L is a copyrighted instrument, which can be obtained from the EuroQol Research Foundation by registering at their website www. euroqol.org. No license fee will be charged for non-commercial use. Reuma2Go is a copyrighted mobile application and accompanying webbased portal was built on the MyOwnMed, Inc., platform (Bethesda, USA) MyOwnMed, Inc.

\section{Authors' contributions}

MD collected data, carried out initial analyses, drafted the initial manuscript, and critically reviewed and revised the manuscript. SR conceptualized and designed the study, collected data, carried out initial analyses, drafted the initial manuscript, and critically reviewed and revised the manuscript. NB collected data, carried out initial analyses, and critically reviewed and revised the manuscript. VSM and MK contributed to the acquisition of data, developed the Reuma2Go-application, and critically reviewed and revised the manuscript. GB designed the data collection instrument, contributed to initial analyses, and critically reviewed and revised the manuscript. JS conceptualized and designed the study, and critically reviewed and revised the manuscript for important intellectual content. NW conceptualized and designed the study, developed the Reuma2Go-application, and critically reviewed and revised the manuscript for important intellectual content. All authors have approved the final manuscript as submitted and agree to be accountable for all aspects of the work.

\section{Funding}

This work was supported by longstanding research support from the Dutch Arthritis Foundation (ReumaNederland), grant number LLP10.

\section{Availability of data and materials}

The datasets used and/or analysed during the current study are available from the corresponding author on reasonable request.

\section{Declarations}

Ethics approval and consent to participate

This study did not fall under the scope of the Medical Research Involving Human Subjects Act, as declared by the locally appointed ethics committee of the University Medical Center Utrecht (reference no. 16-361C).

Consent for publication

Not Applicable.

\section{Competing interests}

VSM is CEO and founder of MyOwnMed, Inc. and has received speaker and/ or consulting fees from Conopco Inc. (Unilever), Janssen Research and Development LLC, Kintai Therapeutics Inc., Novartis Pharma AG, Otsuka America Pharmaceutical Inc., and Sanofi US. The other authors have indicated they have no potential conflicts of interest to disclose. 


\section{Author details}

'Department of Pediatric Immunology and Rheumatology, Wilhelmina Children's Hospital, University Medical Center Utrecht, P.O. Box 85090, 3508, AB, Utrecht, The Netherlands. ${ }^{2}$ Faculty of Medicine, Utrecht University, Utrecht, The Netherlands. ${ }^{3}$ The EuroQol Research Foundation, Rotterdam, The Netherlands. ${ }^{4}$ Department of Public Health, Erasmus Medical Center, Rotterdam, The Netherlands. ${ }^{5}$ MyOwnMed Inc., Bethesda, MD, USA.

Received: 14 August 2020 Accepted: 5 March 2021

Published online: 22 March 2021

\section{References}

1. Haverman L, Grootenhuis MA, van den Berg JM, et al. Predictors of healthrelated quality of life in children and adolescents with juvenile idiopathic arthritis: results from a web-based survey. Arthritis Care Res (Hoboken). 2012;64(5):694-703. https://doi.org/10.1002/acr.21609.

2. Gutiérrez-Suárez R, Pistorio A, Cespedes Cruz A, et al. Health-related quality of life of patients with juvenile idiopathic arthritis coming from 3 different geographic areas. The PRINTO multinational quality of life cohort study. Rheumatology (Oxford). 2007;46(2):314-320. doi:https://doi.org/10.1093/ rheumatology/kel218

3. Tollisen A, Selvaag AM, Aulie HA, et al. Physical functioning, pain, and health-related quality of life in adults with juvenile idiopathic arthritis: a longitudinal 30-year Followup study. Arthritis Care Res (Hoboken). 2018; 70(5):741-9. https://doi.org/10.1002/acr.23327.

4. Sawyer MG, Whitham JN, Roberton DM, Taplin JE, Varni JW, Baghurst PA. The relationship between health-related quality of life, pain and coping strategies in juvenile idiopathic arthritis. Rheumatology. 2003;43(3):325-30. https://doi.org/10.1093/rheumatology/keh030.

5. Selvaag AM, Aulie HA, Lilleby V, Flatø B. Disease progression into adulthood and predictors of long-term active disease in juvenile idiopathic arthritis. Ann Rheum Dis. 2016;75(1):190-5. https://doi.org/10.1136/annrheumdis-2 014-206034

6. Nordal E, Rypdal V, Arnstad ED, et al. Participation in school and physical education in juvenile idiopathic arthritis in a Nordic long-term cohort study. Pediatr Rheumatol Online J. 2019;17(1):44. https://doi.org/10.1186/s12969-01 9-0341-6.

7. Armbrust W, Siers NE, Lelieveld OTHM, Mouton LJ, Tuinstra J, Sauer P. Fatigue in patients with juvenile idiopathic arthritis: a systematic review of the literature. Semin Arthritis Rheum. 2016;45(5):587-95. https://doi.org/10.1 016/j.semarthrit.2015.10.008.

8. Varni JW, Seid M, Smith Knight T, Burwinkle T, Brown J, Szer IS. The PedsQL in pediatric rheumatology: reliability, validity, and responsiveness of the pediatric quality of life inventory? Generic core scales and rheumatology module. Arthritis Rheum. 2002;46(3):714-25. https://doi.org/10.1002/art.10095.

9. Filocamo G, Consolaro A, Schiappapietra B, et al. A new approach to clinical care of juvenile idiopathic arthritis: the juvenile arthritis multidimensional assessment report. J Rheumatol. 2011;38(5):938-53. https://doi.org/10.3899/ jrheum. 100930.

10. Wille N, Badia X, Bonsel G, et al. Development of the EQ-5D-Y: a childfriendly version of the EQ-5D. Qual Life Res. 2010;19(6):875-86. https://doi. org/10.1007/s11136-010-9648-y.

11. Scott D, Scott C, Jelsma J, Abraham D, Verstraete J. Validity and feasibility of the self-report EQ-5D-Y as a generic health-related quality of life outcome measure in children and adolescents with juvenile idiopathic arthritis in Western cape, South Africa. South African J Physiother. 2019;75(1):1335. https://doi.org/10.4102/sajp.v75i1.1335.

12. Otto C, Barthel D, Klasen F, et al. Predictors of self-reported health-related quality of life according to the EQ-5D-Y in chronically ill children and adolescents with asthma, diabetes, and juvenile arthritis: longitudinal results. Qual Life Res. 2018;27(4):879-90. https://doi.org/10.1007/s11136-017-1753-8.

13. Kreimeier S, Åström M, Burström K, et al. EQ-5D-Y-5L: developing a revised EQ-5D-Y with increased response categories. Qual Life Res. 2019:1-11. https://doi.org/10.1007/s11136-019-02115-x.

14. Janssen MF, Pickard AS, Golicki D, et al. Measurement properties of the EQ5D-5L compared to the EQ-5D-3L across eight patient groups: a multicountry study. Qual Life Res. 2013;22(7):1717-27. https://doi.org/10.1007/ s11136-012-0322-4.
15. Janssen MF, Bonsel GJ, Luo N. Is EQ-5D-5L better than EQ-5D-3L? A headto-head comparison of descriptive systems and value sets from seven countries. Pharmacoeconomics. 2018;36(6):675-97. https://doi.org/10.1007/ s40273-018-0623-8.

16. Wong CKH, Cheung PWH, Luo N, Cheung JPY. A head-to-head comparison of five-level (EQ-5D-5L-Y) and three-level EQ-5D-Y questionnaires in paediatric patients. Eur J Heal Econ. 2019:1-10. doi:https://doi.org/10.1007/ s10198-018-1026-7.

17. Ravelli A, Consolaro A, Horneff G, et al. Treating juvenile idiopathic arthritis to target: recommendations of an international task force. Ann Rheum Dis. 2018;77(6) annrheumdis--2018--213030. https://doi.org/10.1136/a nnrheumdis-2018-213030.

18. Petty RE, Southwood TR, Manners P, et al. International league of associations for rheumatology classification of juvenile idiopathic arthritis: second revision, Edmonton, 2001. J Rheumatol. 2004;31(2):390-2.

19. Herdman M, Gudex C, Lloyd A, et al. Development and preliminary testing of the new five-level version of EQ-5D (EQ-5D-5L). Qual Life Res. 2011;20(10): 1727-36. https://doi.org/10.1007/s11136-011-9903-X.

20. McErlane F, Beresford MW, Baildam EM, et al. Validity of a three-variable juvenile arthritis disease activity score in children with new-onset juvenile idiopathic arthritis. Ann Rheum Dis. 2013;72(12):1983-8. https://doi.org/1 0.1136/annrheumdis-2012-202031.

21. Consolaro A, Negro G, Chiara Gallo M, et al. Defining criteria for disease activity states in nonsystemic juvenile idiopathic arthritis based on a threevariable juvenile arthritis disease activity score. Arthritis Care Res (Hoboken). 2014;66(11):1703-9. https://doi.org/10.1002/acr.22393.

22. Youden WJ. Index for rating diagnostic tests. Cancer. 1950;3(1):32-5. https:// doi.org/10.1002/1097-0142(1950)3:1<32::AID-CNCR2820030106>3.0.CO;2-3.

23. R Core Team. R: A Language and Environment for Statistical Computing. Published online 2017. https://www.r-project.org/

24. Stinson JN, Lalloo C, Hundert AS, et al. Teens taking charge: a randomized controlled trial of a web-based self-management program with telephone support for adolescents with juvenile idiopathic arthritis. J Med Internet Res. 2020;22(7):e16234. https://doi.org/10.2196/16234.

25. Lalloo C, Harris LR, Hundert AS, et al. The iCanCope pain self-management application for adolescents with juvenile idiopathic arthritis: a pilot randomized controlled trial. Rheumatology (Oxford). 2020. https://doi.org/1 0.1093/rheumatology/keaa178.

26. Seid M, Opipari L, Huang B, Brunner HI, Lovell DJ. Disease control and health-related quality of life in juvenile idiopathic arthritis. Arthritis Rheum. 2009;61(3):393-9. https://doi.org/10.1002/art.24477.

27. Oen K, Guzman J, Dufault B, et al. Health-related quality of life in an inception cohort of children with juvenile idiopathic arthritis: a longitudinal analysis. Arthritis Care Res (Hoboken). 2018;70(1):134-44. https://doi.org/10.1 002/acr.23236.

\section{Publisher's Note}

Springer Nature remains neutral with regard to jurisdictional claims in published maps and institutional affiliations.

Ready to submit your research? Choose BMC and benefit from:

- fast, convenient online submission

- thorough peer review by experienced researchers in your field

- rapid publication on acceptance

- support for research data, including large and complex data types

- gold Open Access which fosters wider collaboration and increased citations

- maximum visibility for your research: over $100 \mathrm{M}$ website views per year

At BMC, research is always in progress.

Learn more biomedcentral.com/submissions 